\title{
Angiotensin converting enzyme inhibitors v. angiotensin receptor blockers in the management of hypertension: A funder's perspective
}

\author{
J L Makkink, ${ }^{1,2}$ MB ChB; O B W Greeff, ${ }^{2}$ MB ChB, FCFP (SA), MPharmMed, FFPM (RCP) \\ ${ }^{1}$ South African Police Service Medical Scheme (POLMED), Pretoria, South Africa \\ ${ }^{2}$ Department of Pharmacology, School of Medicine, Faculty of Health Sciences, University of Pretoria, South Africa \\ Corresponding author: J L Makkink (jacom@polmed.co.za)
}

\begin{abstract}
Background. Hypertension poses a huge financial risk to any funder/medical aid, including the risk-mitigating strategies provided by the managed care organisations that are required to manage patients with hypertension. The South African Hypertension Guideline states that the choice of therapy - an angiotensin converting enzyme inhibitor (ACEI) or an angiotensin receptor blocker (ARB) - should be based on cost and tolerability. Objective. To assess the costs of ACEIs v. ARBs in the management of hypertensive patients and the prevention of cardiovascular complications for a private medical aid scheme in South Africa.

Method. A Phase IV observational, retrospective cohort study of over 480000 beneficiaries between 2010 and 2011 was undertaken. Hypertensive patients were identified by their chronic medication authorisation and were categorised into three groups: ACEI, ARB and combined groups. A cost-benefit analysis was performed on the claims data, comparing the input costs in rand against the downstream costs using analysis of variance. Results. Data from 28165 patients were included in the study. Based on the health economic analysis that was performed, there was no statistically significant difference in the input costs between the ACEI and the ARB groups. However, a statistically significant reduction in the downstream costs was observed in the ACEI group v. the ARB and combined groups $(p<0.0001)$.

Conclusion. It is more cost beneficial to treat chronic hypertensive patients with an ACEI than ARBs in preventing cardiovascular-related complications. It is recommended that managed care companies continue recommending ACEIs rather than ARBs in the treatment of hypertensive patients.
\end{abstract}

S Afr Med J 2014;104(4):292-294. DOI:10.7196/SAMJ.7593

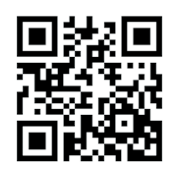

Hypertension poses a huge financial risk to any funder/ medical aid, including the risk-mitigating strategies provided by the managed care organisations that are required to manage patients with hypertension. According to the annual report of the South African Council for Medical Schemes for 2010 - 2011, which was published on 6 September $2011,{ }^{[1]}$ hypertension is the most prevalent chronic disease among medical aid members, $11.7 \%$ of whom have this condition. Considering that the medical aid industry has 8315718 beneficiaries, ${ }^{[2]} 972940$ members will therefore require treatment for hypertension. In terms of the medical aid membership on which this research article is based, the membership is

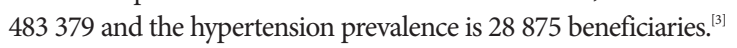

The most up-to-date South African Hypertension Guideline ${ }^{[4]}$ includes a consensus statement on the use of angiotensin converting enzyme inhibitors (ACEIs) and angiotensin receptor blockers (ARBs) for the management of hypertension, stating that the choice of therapy for either an ACEI or an ARB should be based on cost and tolerability.

\section{Objective}

To assess the costs of ACEIs v. ARBs in the management of hypertensive patients and the prevention of cardiovascular complications for a private medical aid scheme in South Africa (SA).

\section{Method}

A Phase IV observational, retrospective (2010 and 2011), cohort study was undertaken involving over 480000 beneficiaries of a restrictive, private medical aid in SA. Hypertensive patients were identified by their chronic medication authorisation. All claims data of hypertensive patients who were registered members of the participating medical scheme and received either an ACEI or an ARB in their hypertensive treatment regimen were included. Claims data for 2010 and 2011 were assessed. Hypertensive patients who claimed $<90$ days for their chronic medication were excluded from the study.

All the ACEIs and ARBs that are available in SA, were identified via their unique National Pharmaceutical Product Index (NAPPI) codes as registered with the Medicines Control Council of SA.

Hypertensive patients of interest were categorised into three groups: - ACEI group

- ARB group

- combined group (patients that received an ACEI or an ARB in their treatment regimens during the 2-year period under review).

Costs associated with the payment of the chronic medication were used as the input costs in the 'cost-to-benefit' health economic analysis.

The cardiovascular disorders/complications, for which hypertensive patients were treated during the 2-year period under review, were identified via The International Statistical Classification of Diseases and Related Health Problems, 10th Revision (ICD-10) codes.

Costs associated with the treatment of the cardiovascular disorders/ complications during the 2-year period under review were used as the downstream costs in the 'cost-to-benefit' health economic analysis. The downstream costs were used as a proxy to compare the clinical efficacy of the two classes of drugs in preventing cardiovascular complications.

A cost-benefit analysis was performed on the claims data, comparing the input costs in rand (ACEIs v. ARBs as chronic medication) against the downstream costs (treatment of the cardiovascular disorders/ 
Table 1. Total and per patient input and downstream costs per group

\begin{tabular}{|c|c|c|c|}
\hline & ACEI & ARB & Combined \\
\hline \multicolumn{4}{|l|}{ Patients, $n$} \\
\hline Total, $N$ & 19901 & 7029 & 1235 \\
\hline Male & 11742 & 3654 & 655 \\
\hline Female & 8159 & 3375 & 580 \\
\hline \multicolumn{4}{|c|}{ Input costs (ZAR) } \\
\hline 2010 & 16256963.95 & 7944473.21 & 2705300.80 \\
\hline 2011 & 17094598.74 & 8109171.80 & 2852782.20 \\
\hline Total & 33351562.69 & 16053645.01 & 5558083.00 \\
\hline \multicolumn{4}{|c|}{ Cost per patient, average } \\
\hline 2010 & 816.89 & 1130.24 & 2190.53 \\
\hline 2011 & 858.98 & 1153.67 & 2309.95 \\
\hline \multicolumn{4}{|c|}{ Downstream costs (ZAR) } \\
\hline 2010 & 119635140.87 & 53534678.73 & 26123522.28 \\
\hline 2011 & 130263702.72 & 63763614.29 & 31269660.78 \\
\hline Total & 249898843.59 & 117298293.02 & 57393183.06 \\
\hline \multicolumn{4}{|c|}{ Cost per patient, average } \\
\hline 2010 & 6011.51 & 7616.26 & 21152.65 \\
\hline 2011 & 6545.59 & 9071.51 & 25319.56 \\
\hline
\end{tabular}

Table 2. ANOVA of downstream and input costs per group

\begin{tabular}{lcc}
\hline Costs per group & Cost $($ ZAR $)$, LSM $( \pm$ SE $)$ & $p$-value \\
\hline ACEI & $6278.55( \pm 133.19)$ & $<0.0001$ \\
$\quad$ & $837.94( \pm 133.19)$ & $<0.0001$ \\
Downstream & & \\
Input & $8343.88( \pm 224.10)$ & $<0.0001$ \\
ARB & $1141.96( \pm 224.10)$ & $<0.0001$ \\
Downstream & & \\
Input & $23236.11( \pm 534.64)$ & $<0.0001$ \\
Combined & $2250.24( \pm 534.64)$ & $<0.0001$ \\
Downstream & & \\
Input & &
\end{tabular}

complications). Because there were many independent variables associated with single members that required analysis, an analysis of variance (ANOVA) model was used.

\section{Results}

Data of 28165 patients were included. Total input costs and downstream costs are reflected in Table 1 for the ACEI, ARB and combined groups.

An ANOVA model was used to determine the statistical significance in the variances observed between the input costs v. the downstream costs in the three groups under review (Table 2).

When comparing the least squares means (LSMs) of the input costs of the ACEI group v. the ARB group, there was not a statistically significant difference between these two groups $(p=0.24)$. However, when comparing the LSMs of the input costs of the combined group v. the ACEI and ARB groups, a statistically significant difference was observed ( $p=0.01$ and $p=0.05$, respectively) (Table 3).

When comparing the LSMs of the downstream costs in the three groups under review with one another, a statistically significant difference was seen in all three instances $(p<0.0001)$ (Fig. 1).

\section{Discussion}

Based on our health economic analysis, there was not a statistically significant difference in the input costs between the ACEI and the ARB groups. However, a statistically significant reduction in the downstream costs was observed in the ACEI group v. the ARB and combined groups $(p<0.0001)$. Patients in the combined group, that were treated with an ACEI and an ARB during the period under review, were least cost beneficial. A limitation of the study was that the groups were not stratified for baseline cardiovascular risk.

Table 3. Comparison of LSMs by data/type on downstream and input costs between groups

\begin{tabular}{|c|c|c|c|c|c|c|}
\hline & \multicolumn{2}{|c|}{ ACEI, $p$-value } & \multicolumn{2}{|c|}{ ARB, $p$-value } & \multicolumn{2}{|c|}{ Combined, $p$-value } \\
\hline & Downstream & Input & Downstream & Input & Downstream & Input \\
\hline \multicolumn{7}{|l|}{ ACEI } \\
\hline Downstream & - & $<0.0001$ & $<0.0001$ & $<0.0001$ & $<0.0001$ & $<0.0001$ \\
\hline Input & $<0.0001$ & - & $<0.0001$ & 0.2435 & $<0.0001$ & $<0.0104$ \\
\hline \multicolumn{7}{|l|}{ ARB } \\
\hline Downstream & $<0.0001$ & $<0.0001$ & - & $<0.0001$ & $<0.0001$ & $<0.0001$ \\
\hline Input & $<0.0001$ & 0.2435 & $<0.0001$ & - & $<0.0001$ & 0.0559 \\
\hline \multicolumn{7}{|l|}{ Combined } \\
\hline Downstream & $<0.0001$ & $<0.0001$ & $<0.0001$ & $<0.0001$ & - & $<0.0001$ \\
\hline Input & $<0.0001$ & 0.0104 & $<0.0001$ & 0.0559 & $<0.0001$ & - \\
\hline
\end{tabular}




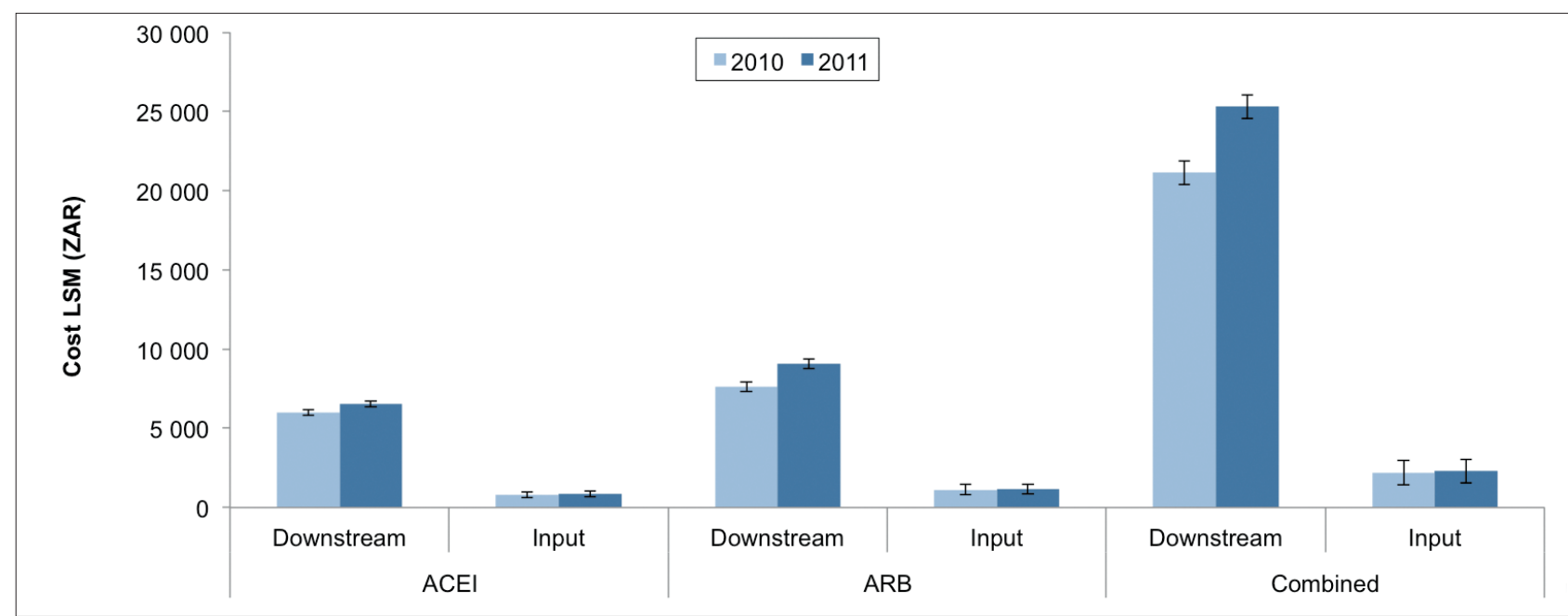

Fig. 1. ANOVA of cost least squares means (LSMs) v. data source $(\mathrm{p}<0.0001)$. (ZAR = South African rand; ACEI = angiotensin converting enzyme inhibitor; $A R B=$ angiotensin receptor blocker.)

\section{Conclusion}

This health economic analysis reveals that it is more cost beneficial to treat chronic hypertensive patients with an ACEI than with ARBs to prevent cardiovascular-related complications. It is recommended that in the drug utilisation review process, managed care companies continue with their effort in recommending ACEIs rather than ARBs in the treatment of their hypertension patients.
Acknowledgement. We thank Dr M van der Linde for his statistical support.

References
1. Council for Medical Schemes. Annual Report 2010 - 2011. Pretoria: CMS;85. http://www.medicalschemes. com/files/Annual\%20Reports/CMS-AR-2011-WEB.pdf (accessed 19 February 2014).

作 com/files/Annual\%20Reports/CMS-AR-2011-W
3. POLMED. Key Trends Report. January 2012;22.

4. Seedat YK, Rayner BL. South African Hypertension Guideline 2011. S Afr Med J 2012;102(1):57-84.

Accepted 18 November 2013. 